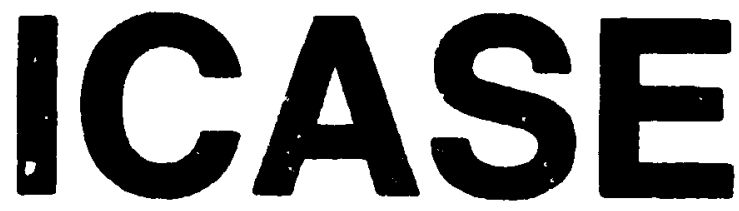

\title{
SIMPLIFIED PHASED-MISSION SYSTEM ANALYSIS FOR SYSTEMS WTTH INDEPENDENT COMPONENT REPAIRS
}

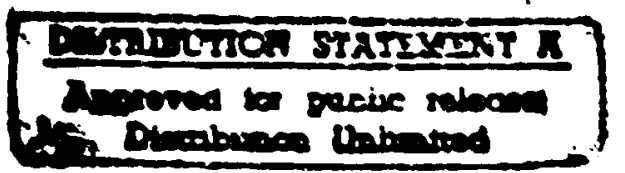

Arun K. Somani

NASA Comiract No. NASI.19480

March 1996

Instisuse for Computer Applications in Science and Engineering NASA Langley Research Cenier

Hampion. VA 23681-0001

Operated br. Universities Space Reseanch Association

$1+1$

National Aeronautics and Space Administration

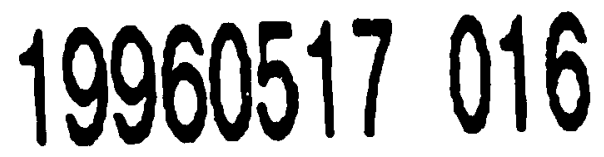

Langloy Rescarch Center

Hampton. Virginin 23681-0001 

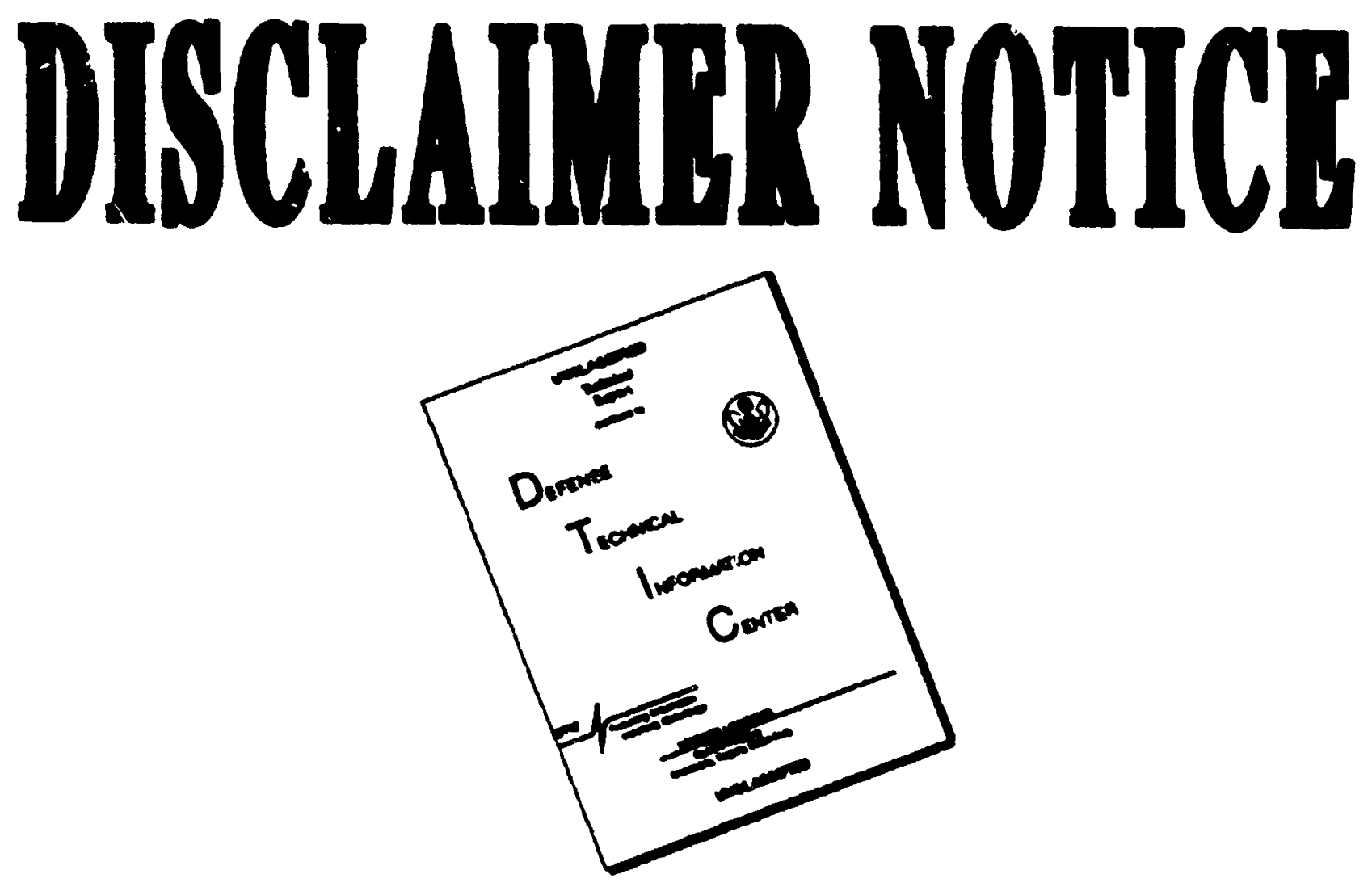

THIS DOCUMENT IS BEST QUALITY AVAILABLE. THE COPY FURNISHED TO DTIC CONTAINED A SIGNIFICANT NUMBER OF PAGES WHICH DO NOT REPRODUCE LEGIBLY. 


\title{
Simplified Phased-Mission System Analysis for Systems with Independent Component Repairs *
}

\author{
Arun K. Somani \\ Dept. of Elertrical Eng.. and Dept. of Computer Sci. and Eng. \\ Iniversity of IVashington \\ P O Box 352500 \\ Seattk. WA $98195-2500$ \\ Tele: $(206)$ 60i-1602 \\ esnail: (somani.arun) $\hat{q}\{$ fee.cs\}.washington.edu
}

\begin{abstract}
Accurate analysis of reliability of system requires that it accounts for all major variations in system's operation. Most reliability andyse assume that the system configuration. success criteria. and component behaving resuain tbe same. However. multiple phases are natural. We present a nex computationally efficieat technique for analysis of phased-miscion systems where the operational states of a system ean be described by combinations of components states (such as faule trees or assertions) Moreover. individual components may he repaired. if fuiled. as part of system operation but repairs are independent of the system stale. Fot repairable syatems Markov analysas techniqurs are used but they suffer from state space explawion. That limits the size of system that can be analyzed and it is expensive in comput ation. We avoid the state space explocion. I be phace algetra is used to accoual for the effects of variahle configurstions, repars. and success eriteria from phace lo phase. Our technique yields exact (as opposed to approximnte) resulus. We demonstrake our technique by means of sereral examples and present numerical results to show the effeess of phases and mpairs co the system reliahility / availability
\end{abstract}

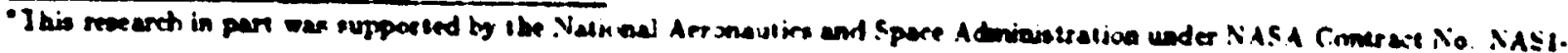

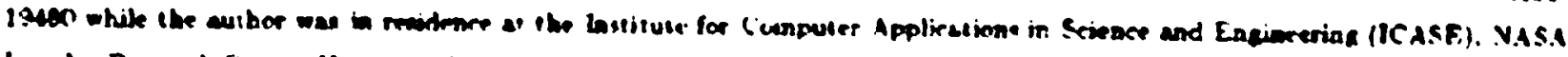

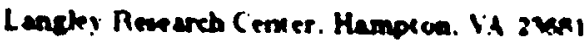




\section{Introduction}

Accurare analysis of reliability of syatem requires that it acrounts for all major variations in system s operation. Most refiability analrses assume that the system configuration, success critetia, and camponent behavior remain the same. However, nultiple phasse are altural. The system configuration. opasational requirements for individual components. the success criteria. and the stress ou the components (and thus the failure rates) may vary (rom) phase to phase. Various techaiques and took have been developed :1;-[1'? to analyae single miscion system. Phaced-mission system analysis also has recrived substantial attention by researchers [5] - [12].

Depending on the requirements during different phases. different componcats may be placed in or removed from service of repained during a phase to balance the sustem reliability and the ccot of operation. The sucress of a redundaney management seheme determines if a systcm is operational or not. The usage of subsrstems may also vary from phase to phase and subsystem supporting thooe services may remain idle or may be switehed aft. Furthermore. the duration of any phase may be deterministic or sandom. All these variations affect the system reliability. For example, in an airplabe system. landing gear and its asenciated control subeystems ase not required during cruising phare So exact analysis should not ignore such bebaviors.

Sometiones the effects of indwidual phases may be ignored in fovor of simplet anaysis. For example. in case of landing gear example. if the failure rate of landing gear is very small for All phases, counting the failure of landing gear during eatise lugbt snay not affect result significantly. On the orher haod in another example. in opace mimaion. The first phase (launch) is the most severe and uses many sumponents for a fer aunutes rbose failure rates are high. Csing the high failure rates and exposure ume equal to the miscion time for thoce componencs is graranterd to result into urekess analysis

In uppraximate andyas, nuxet of the time only conservative extimates are made yielding the worst case unreliatility of the aystem. One adverse effert of this is that Use syatems may be over-deasigned A nrore accurate analyess avoids this. in particular whete there may be wide variations in the paramruers and system configuration

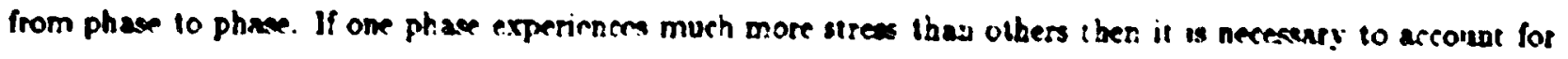

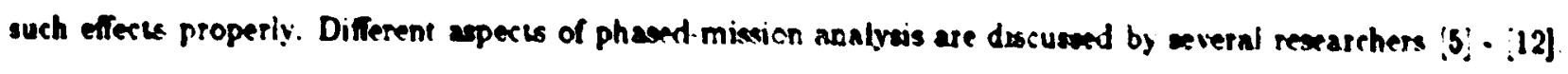

A phased-miswion syixem can analyzed necurately using Martor nethods. Hownes that suffers from statmepace explocion and is expensice in time In :12! the authors presented a methodolocy to analyze nonrepairable phased-mission systems in which falur ratea, configuration and succeas eriteria may vary from phaxe in phase. Moreover the succese criteria can be specified using faull iress or an equivaleat representation. I majority of systems can be represoted using fault trees. They solve the symem without gemerating a Mlarkov chain. Phames are handled one at a sime co compute sthe oresall ubreliability of the entive miseion. This technique us computationally less erpenssive. As a revult, large systems can be managed 
It is possible that during long nissions, repairs are carried out en components or subsystems 10 ibcrease the life of system. For example. in a long manoed space mission. failed cornponencs will be repaired and must be appropriarely accounted for in the analysis. The form of repair may vary. For example, a syatem may be completeby replaced by anotber mew system or only maintenance cbeck ssisy be carried our and aubastems are repaited in the conventional sense. Nartor analygis techniques can be used but. as stated earlier. may sequire to manage huge state apace and computation time. Wie extend the methodologe of [12] in this paper significantly by including repairs of independeat components. He require that the system success criteria is dependent only on the state of individual composent and as long as the success criteris is satisfied. the phase remains opesational. The results of this paper allows analysis of large systems with componen: repairs efficiently. In the descriptions befow: we will assume that a reader is gene:ally familar with .Hartor chaib-based analysis. We will use it to describe certuin situations but will propose a methodology which does not explicitly generatr the stave space.

In all of this rort, phase transitions are assumed to be instantanecus and no loss of gain is assumed in the probability of any particular state in Martov chain. However, due to change in success eriteria. some opesational states may be seen as failure states in tbe next phase and are treated as lacent failures for analysis. For example. if the landing gear develops a problem during cruising. the thgint will continue in air but the last phase. landing. may not be succeasful. Thus the landuig geas failure is latent. If the failed leading grar can be repaired duriug the bight. theb the effect can be accounted for in the analysis.

We present sone retated wort in the next section Then we describe some soncepts which we will use throughnut the paper. Following tbat ax present bandling of repairable systems and our methodology ro manage computation efficiently. We present a few examples and demonstrate the effectiveness of our work. In all cacs. the results are compared with EHARP [10] results which conpule unreliability of phased mission symem correctly as if follows state-cosiatr mapping from phase to phase

\section{Related Work}

Esary and Ziehms [j] diccuss analysis of multiple configuration systems during difirrent phases of mission using reliabilit! block diagram (RBD) Fos phase p each component is represented by a xeries of a blocks. ope

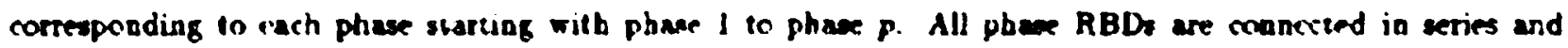
solut son of this RRD correctly predicts the reliability of the three phase system. Tbis results ia a large RBD and failure of enmponents cannot be accounted for. Pedas and Sarma $\mid 6 j$ entooced this tecboique so systematically cancel out the common events in earlier phases which are accoubted for in later phase in the RBDs. We will user Esary and Ziehmes prpreseatation for componcots in various phanes for adysis but perform the compulation difierently: 
Alum and At-Snggaf [i] use Markm chain and Smotherman er. al. [9] use a non-homogeneous Narkov model to include phase changes in the model. The Markov chain in both cases can be very huge. It should be pointed out that the latter lechaique allows the most accurate andysis if phase changes are bot smooth. However, this requires lare amount of storage and computation time en solue a system, thus limiting the type of system that can be analyzed. Somani et. al. :10! presented a computationally efficient method to analyze multi-phased syutems and a new software tool for reliability analyses of such systems. A system with variable configuration and success crikeria results is difterent Markov chains for differeat phases. Instead of geperating and colving in overall Nartor chain. they advocate generating and solving eparate Martor chains for individual phases. The iariation in succen criteria and change in system configuration from phase 10 phase are accommodaced by providing an efficient mapping procedure at the transition time from one phase to another. Wibile analyzing a phase, only the states relevant to that phase, are considered. Thus each individual Nartor chain is much smalles.

lising a similar approach. Dugan [8] suggered anothes method in which a single Markov chain with state space equal to the union of the state spacrs of the individual phase is generated. The transutioas rates are parameterised with phase numbers and the Marken chain is solved p times for $p$ phaces. However. the failure eriteria is aloo the union of all phases failure criteria as any failed state in any phase is coosidered failed state for the whole system. Thus. the scheme is only applicable is the success criteria does not change over the phases.

\section{Distribution Functions with Maes at Origin}

As in [12]. we will use the cosceps of cumulative dist:ibution functions with a mas at the origin in our wo:k Consider a random variabie.$t$ with cumulative distribution function given by

$$
F_{\lambda}(t)=\left(1-e^{-\lambda T_{1}}\right)+e^{-\lambda T_{1}}\left(1-e^{-\lambda t}\right)
$$

This function has a max at the origin given by $P\left(X=0:=\left(1-e^{-\lambda T_{i}}\right)\right.$. The second term represents the colitinuouk part of the diantribution function

Io corder willustrale the use of such a CDF. consides a component with a constant failuse rate of $\lambda$ that is used in a phaeed raiasion systern. Asoume that the system has just complered one phase of duration $J_{1}$ aed is currently in the second phese. The above CDF can be aceicoed as the failure probability distribution of the component in the eccond phase. The fist term in the stove expresaion represents the probability that the componeat has already failed in the fire phase Tbe second term represents the failure probability distriburion for this component for the second phase. The time origin for the eecond phase is reinitualized to the beginning of the phase. Wie will use such distritution functions to mpresent failure probabilities of individual componente duriug different phaces. 


\subsection{Component Model with Repairs}

The model described above can be extended to iaclude separ for a component. Let $\lambda$ be a component whose failure and repair rates in phase $p$ ane denoted by $\lambda x_{p}$ and $\mu x_{r}$. respectively. Failure and repair times are essumed to follow exponeatial distribution. He define

$$
a_{x_{p}}(t)=e^{-i \lambda_{x_{p}}+\alpha_{x_{p}} \nu_{01}} \text { and } \partial_{\lambda_{p}}=\frac{a x_{p}}{\mu x_{p}-\lambda_{\lambda_{p}}}
$$

where $t$ is the time afier the system entered the phase $p$. Wie can compute potabilities of companent $x$ being operational (up) or mot-operational (failed) ty solving a iro stake Markov chain for the component. At the beginning of a phase a componeut may be in an operationaj or failed state With either of the initial states. the component mas be operational or failed at the end of the phase due wo failure and repairs involved during that phase. To compute the probabilities for a component wo be operational or failed at the end of the phase. we need to compute the probabilities of all the four possible cases.

We nill follow a 4 character suffix with probabilities. The first character is the aame of the compossent (i.e. $X . Y)$ The second sharacter is $u$ for up of $f$ for failed and is acociated with the starting state of that component in a phase. The third character is $u$ or $f$ as earlier It can also te $c$ if it refers to probability at ibe end of a phax or a $b$ if it refess to the probability as the beginaing of a phase. The fourth characte: $p$ is for phase aumber. The first and the fourth characters will change with components or phase number we are dealiag with. If it is given that the component $X$ is up. then the probabilities that it will remain up or failed after time $f$ bas elapsed in phas $p$ are given by

$$
F x_{\text {sur }}(t)=a x_{r}(t)+J_{\lambda i}+\left(1-a x_{F}(t)\right)
$$

and

$$
p_{x_{u f p}}=\left(1-a_{x_{p}}(1)\right) \cdot\left(1-3 x_{x_{p}}\right)
$$

Similarly if it is given that component $X$ is failed. then the probubilities that it will temain up or faled are givea b!

$$
p x_{i u r}=3 x^{b}+\left(i-a x_{r}(t) !\right.
$$

and

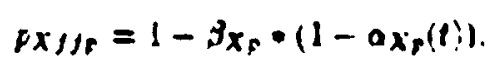

If the probabiluties :bat compopent $I$ is initially up and failed at the beginaing of the phace $f$ are print and

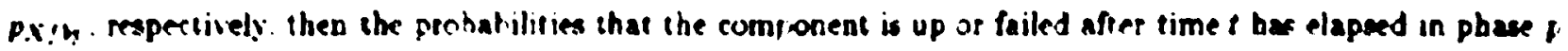
are given b!

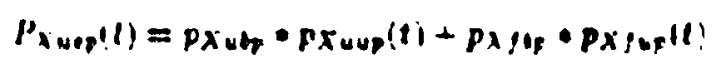


and

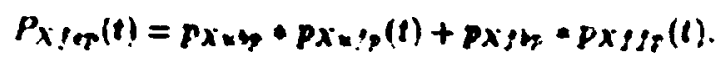

The overall operational and failed state probabilities for a componeat can be evaluated at the ead of pbase $F$ by suhatituring $t=T_{p}$ in the the above exprescions. They inilude the mass at the origin (the initial up or failed st ate prohabilities!. $T$, is the duration of phase p. For example, suppose for a conponed $X$ in phase 1 . if $\mu_{\lambda_{1}}=9=\lambda_{x_{1}}$.

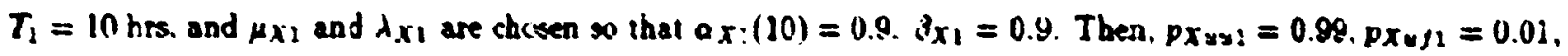

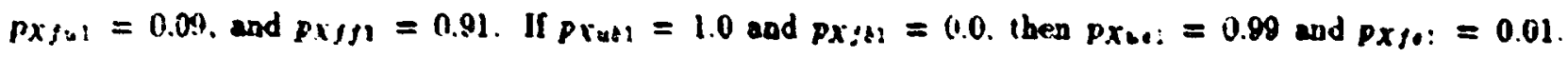
If. on the other hand. Fxis1 $=0.99$ and px;s: $=0.01$. then p.ru: $=0.99 \cdot 0.99+0.01 * 0.09=0.981$ and $p_{x \text { les }}=0.99 * 0.01+0.01 \cdot 0.01=0.019$.

\section{Phased-Mission and Component Repairs}

In analyas of reliable system when a system enters a failure state during a phace. the entire missian is considered whave failed. So the next phase only begins. if the system rernaina operaticnal during all previons phases. If the components are not repaired. the success os falure of system depends on the cumulative cperational probabilities and success criteria defined by the combinations of tates of operational components. In such cases. as shown in [10]-[12]. one can compute the success probability of the whole mission.

Notice that a system state may be considered as a failed state in phace p but may be a success state in the mext phase due to a less stringent euccese crivesia. This is acceptable behavior even in reliable systems. In such cases. all state occupation probabilities (SOPs) accumulated in such states up 10 only phase p are considered to be contributing wowands failure of misswer. Thereafter thes are conadered a part of surcese. This is key in correct annlysis of a phased-missron system and is implemented in EHA RP.

In certain sisuations. hownes, it is pxesible to desigo systems tbat include repairs to keep reliability high. For example. in a long mision. to improve reliability and performance, it may he advisable and decranary to carry out repairs on system duriog operalion of system. Since in different pbases succens eriterims vary. all of the componeats may not be used in all phanes. When cestain components are not required fo: the system operation. they may be repaired and employed agan in the following phases. The repairs are to remain in reariy state fos future phases. In phases wheb repairs are cartied out, the system status is not affected by the componeats uader repairs. In Martow cbain representation this implies that the repai: transisions are from failed states to failed atetes of operation states to operntion utalus In suct caces. we can compute reliability mote efficiently using the approach of this paper.

For example cuasider two components. A and B. aystem which are used alternately in two cunseculive phases. 
Both components can fail in either phase but only the componeat not in use in a phase only undergoes repairs in that phase. The system operational and failed states for the two phase are shown in Figure 1.

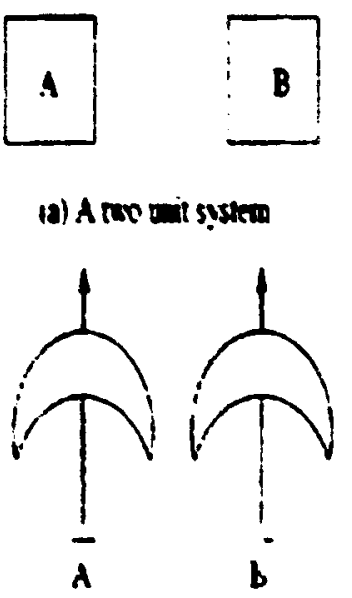

B is repeired A is repined

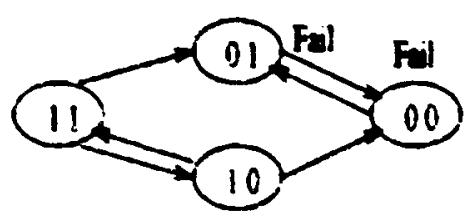

Pure 1

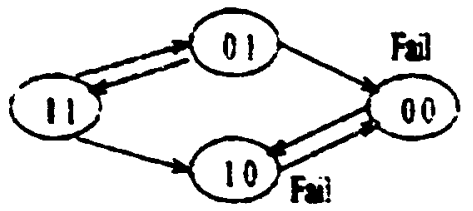

Puxe?

Figure 1 . A two component system and its faled states

In a repaizable system. it is alsu presible that the system may ente: from a failed at ate to soccess state within the stume phase. Since the surcess criteria is specified using combinabrial methods. this will happen if the system up or failed state depends on a componect which is also heing repaired in that phase. Io such caser. wase of combinatorial metbods only will not allow us to pay us attention wo the fact the system may transit through the faijed staus. One important consideration here is that must such irabsitions be albwed in the same pbare? Strietly speaking. for critical operafion syxtem. once a syatem failure has occurred, it is catastrophic and must be ireated as such. This is. theseforr. ohviously not allowed for reliable system as they are consider.ed faled once the eystem enters a failed atate. In that case, she :echnique of this paper cannot be applied a tbe system does not remain symanetric. Such wastems can anly be solved using the techniques dezcrited in $[i, \Omega .19]$ and the took such as K.HARP.

There are many other scenario where the eechaiques develeped in this papet will apply In this papet we are asuming that component repairs are undeprendent of system states and are carried ous based on the component states only. the surcess criteria may be such that this does nin impart the results. If only those components are repaired that are not participating in the operation of a system in that phare theo the success criteria automatically satisfies the requitement for correct anslysis. This is the case in the example of figure 1 . This is beciaus the up or failed stake of euch comprovents woulf not affert tha analysis as the! do not affect the success criceria. Alcmatively, if the approach for succeas that "all is well if the end is well." then also this analysis can be und What we mean hy this w tbat if it is the systrm staic at the end of a phase that counts and transient seners during the operasuon do not inatlet (or de net matlet "much"). then this techaique can he used 
Anocher question that arises is that can one start the next phase of bot in a state where the system is cousidered failed. For refiability analysis. the obvious ansmer is no as the system has already failed. But in some analysis. like periormability ar aviilability. this is obviously acreptahle. Thus bandling of such states depends on the system definition. This is open to interpretation. For availability and performability analysis. if a particular phase may fail in a particulax combination. that combination may be considered further as the system may: recover from it due 10 repaiss. In such cases. it is possible. that the next phese can begin. eren if the system is in a faled state ciace it is possible that the system is brougbe back up in an operational statc. So. in esennee we may be more interested in the availability of a s!stean dursog a particular phases and not reliability according to definition of reliability. The availability then can be user to compute : he pesformability of the system. This analysis is bevond the scope of this paper and is anhject of cur further research

\subsection{Examples Used in the Paper}

Io describe and sbow the effectiveness of the rork bere. we wil: use the folioning thice examples

Exnmple 1. Our fint example is the the one deseribed earlier of a two components $A$ and B. system tha: can be represented using four states in a Markor chain as sbown un Figure 1. One component is repaired while the other is used for the system operation. Thus failure and success of system depends on the component bejng uned. This may correspoud to a factory foor where two machines are alterbately uxed while ol her goes through its repair (or maintenance) cycle and is repaired as needed to bring it up to the fully operational sate. We will consider a four phased system with differeat paramerers and phace durativos

Exanmple 2. The second example is of a aligbtiy. bigser system where we have more scope to stow changes in system configuration that lead 20 system failure and suecess and finer points of the compiexity involved in analyris. This eystem consusts of three component. A B. and C. One of these components may be sepaired in a phace while the other two are woed in a phase in sone combirations. The system remains operational as long as the sperified succes criteria is satisfied The success criterts for each of the thre phases is expressed using fault trees. Each time we use imo omponents and dependiag on the requirements we may requise both or any one of thein operatiunal. Tbe failure rates of three components are $\lambda_{4}$. $\lambda_{3}$. acid $\lambda_{e}$. respectively. and these are sefined for each phase exparately. The repa.: rates for these parameters are $\mu_{0} . \mu_{b}$. and $\mu$. respectively. Two Insticulas configuration two out of the three component are shows in Figure 2 a

1 Markov chain for a three imponent syotem with all repair ares is also shown in Figure 2b. Io tise Markov chain representation. 3tuple represconts a state indicatiug the stalus of the three components respectively. A "I" repreants that the corrmponding component is alive and a $V^{\prime}$ sepresent that the component has failur For 


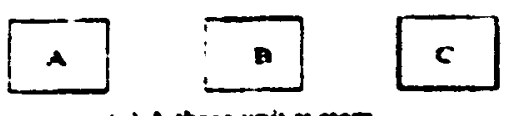

(a) A bere und ny mem
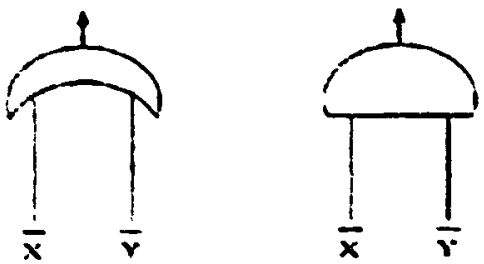

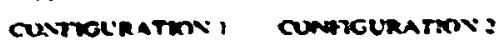

(n)

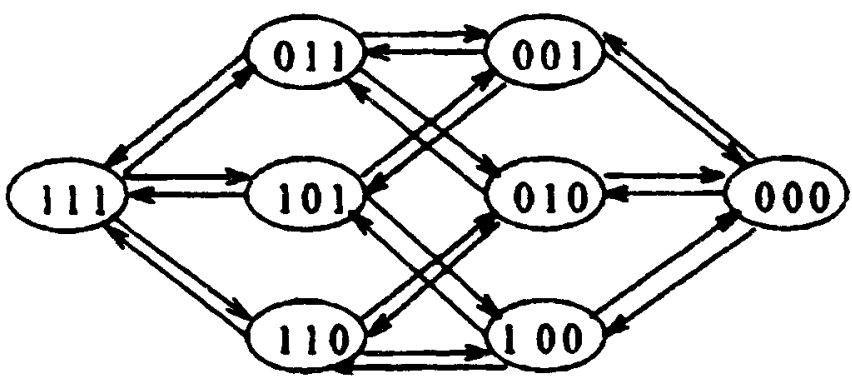

Martor Chain for a three component system with repairs

(b)

Figure 2: (a) Tro configuration of a three component system and (b) the Markor chain with all failure and repair ares.

example, state (i01) implies that component B has faled and the other two components are alive. A transition. from one state 10 ano:her state bas a rate asenciated with it which is the failuse rate of the companent that fails or repair sate of the component that is repaired. For example. a transition from state 1011 ! wo state (010) has a transition rate of $\lambda_{c}$. States marked $F$ are failure states. Sumilarly transition from state $\left.i 010\right)$ to state $(011)$ has a transitiou rate of $\mu$.

Depending on success criteria and sustern parameters. only some of these states will be success stares in each phase. Some of the arcs may have 0 rate ascociand with them or the! inay not exist For cxample. if a repair is not artive. the cortesponding are may be dropped. We whll use several combination of 8 mo mossible success criterias in a three phase system. In esch of these eases. One of the compotrenis will no' be uard in each phase and will be repaired. The component parameters and phase duration may rasy.
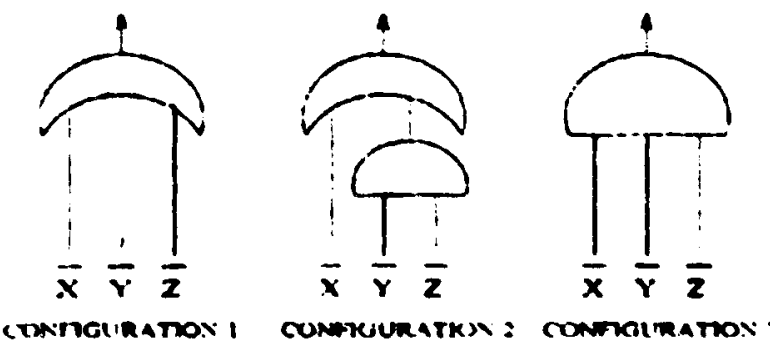

Figure 3. (a) Three configuratise of a three romponent systern.

Example 3. For our third exanuple. we will use all is weli, if the end is well approanc " We will use the subse three compenent system of Example 2 but will use all tbree components in each phace The three phase configurations to be used are showil in Figure 3 The romponents are also repaired in each phase. As tong as a 
phase terminates satisfying the success criteria We will compare the results with the case when repair arcs are not allowed from the failed state (analysis perfor-ant using ERARP! and to notice the inaccuracies incurred in computation.

\section{Phased-Mission Analysis}

Suppoes we are given the fajlure, and repair sates for each component for each phase aud the success criteria for each phase. The component failure and repair rates may be phace depeodent. We asume that the phase durations are deterministic.

To account for phase-deperdent failure and repair sates. we tase the component model for failure and surcess dist ribution with mass at origin fir each componect as descrit ed in Section 3.1. We compute the distribution of failure for each componeat for each phase using the initial (beginning of that phase! up and failed probabilities and failure and repair rates for that phaoe. The failure distribution function is describer in Lquation $i$. In there. time $t$ is nieasured frum the beguning of phase $p$ sol that $0 \leq t \leq T_{r} . T_{r}$ represents the duration of phase $f$. This

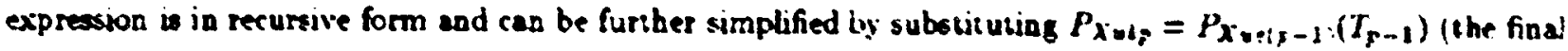
values for phace $p-1$ as the initial ialues for phase $p$ ). But we prefer to leave the expressions for each phase as they are in the recursive form as we aeed individual phase components in out conputation to combine the results for all phases rogether.

Notsce that a compunent may be up of failed in any phase with the distributions described in: Equations 6 and $i$ irrespective of its stafus in the previous phose due to failure and repairs of that comporrent in that phase. This is in contrast 10 non-repairable systetn where a component ean be up only if it is up at the beginning of the phase.

If the failure and repar rates are nge deprendent then one would have to cousider lime as a global parameters. i.e. time starts with the beginaing of a mistion and phax $p$ starts at time $C T_{5-1}=\sum_{i=1}^{r-1} T_{1}$ aod finishes at

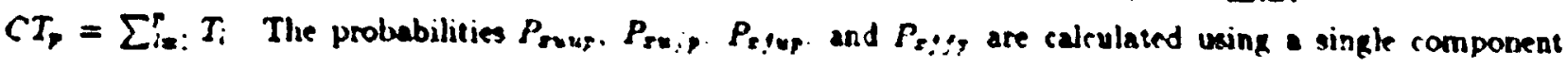
model where both failure and sepair raves are fubction of time. The resuitiug componeal behavior us represnted using a more complienurd non-homagenmus Markor chain for nibich appropraale differential equations can be rasily dercloped. Bowever, solution of tbese equations doe nol have a closed form solution for general $\mu(1)$ and $\lambda(t)[14]$. In sperific cases when $\mu_{x_{r}}(t)=0$ and only failure rate $\lambda_{x_{p}}(t)$ is a iunction of time, we can

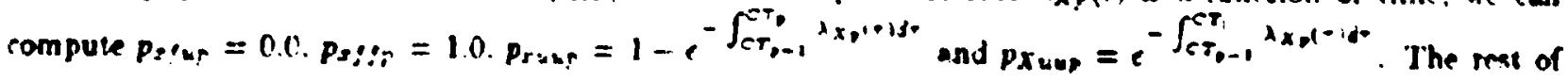
the computation remans the same. 


\subsection{Management of Phase-Dependent Success Criteria}

The success criteria in different phases may be different for a variety of rescons including (i) nor all components are used in all phases. (ii) the expected performance out of individual components may be different in different phases. (iii) individual subsystems may be dmpped or included in the systenz. (iv) the dropped (not used) suhsystern may be repaired. and $(v)$ additional redundancy may be provided or redundaney levels may be reduced for certain casts.

Dne wa change in success criteria and repairs, it is possible that some conbination of failures of components in one phase leads to failure of the system whereas the same combination does wot lead io failurr in some othes phase. 'The following five scenassos arise ill computation at the time of phase transition from priase $f$ to phase $p+1$. The first four of these are the same as described in i12j lor nub-repairable system

1. A combination of component failures does not lead to system failure in both phases $p$ and $p-1$

2. A combination of componen: failures leads to system failure in both phass $p$ and $p-1$.

3. A combination of component failures does not lead to system failum in phase $p$ but leads to systern falure in phase $p+1$.

4. A combination of component falures leads in system failure in phase $p$ bet not in phase $p+1$

5. Due to repair tbr system in a failed state may trancit hack to a up state

Tle inecbanism to compute unrelsabilisy of a system at time $t$. whose behavior is described using fault trees for differeat pbases. is 10 compute the protubilities of all events at lime $t$ and then evaluace the foult tree wing those event probabilities. The events here are wtetber components are up or failed. We already bave described merhanism to compute: the eirnt probabilites at im- t in Sertion 3.:. Ising tha! we can evaiuate the fault irer applicable at tisnet

The first three cans listed atove direct!y contributes towards unreliability or reliability and are taken care appropriately by a fault im etaluation. Fault iree for a pliax include failure coinbinations which remain sommon in all phaes and thoop combinations which are considers as success eatier bui are treated as frilure in the current phace. Such combinations can be treaied as fallure combiastious ovet all pbace as the system eventually fails in phase where this combination leads insystem failure. These are referred to as bitent failures in [11]. Hence applying the failure criteria of the currect phases 10 previons phacs is correct and appropriate The unreliability can tre evaluatrd ty evaluating the fauli tree for current phase.

However, in order to compute correst unreliahility. ne must compute the pmbahility of the system teing in fuled state in an! phase. The fault tree evalualion for the current mhase does not include the last ino cases 
If a system slate is a failed state up to phax $p$ and then. it is a up state, the prohability arcumulated in that state up to the end of phase $p$ must he counted torards unreliability. Suxh falure combinations can be identified using phase algebre as described in [12].

The only additional complication now is due to repars as listed in ease 3 . We meed to identify the prohahility that is once associated with a failed state in a previous phase but bow is been associated with a success state. A siraightforward ecaluation of faule tree assonciates sich probabilitios with success states that get counted as reliability. We need to ijentify probabilities. This ian be done hy extending the phase algebra.

Notice that chen if the surcese criteria remains the last scenaric must sill the analyzed and acr uated for. Also notice that in mose sises we ascume that the components being repaired are thooe which are not bring required for systicm opersicion in that phase. Therefore. the suesess criteria rill not mmain same ouct all phases.

In a Markov chain-hased anaiysis. it is easiet 10 ieep trach of te systena stales. and therefore change in system success enleria could be easily accounted fa:. However. in ihe case of a favit tree. this change naeds in Deccounted for by considering those combinations wheu the sysietz niay $x$ may not fail at the time of a phase iransition.

Tbus our methotolng consists of the foliowing steps. We divide the sysiem unrehabilly of a phased miscion system into three parts: (i) common failure combinations: (ii) phase failur combinat wons. and (iii) .erair to suecese comhinations. Common failure combinations are specified by the fault tree desetiption of the current phase. Phase failure combinations and repair to success comilaatrons are identified using the phase algehra. 'These includes all those factors which dewribe failure un prevous phases but are no: coasidered as failure now or those fows which occurred from faijed combinations to success comivinations

\subsection{Phase Failure and Repair to Success Combinations}

Io determine phase failure and repair to success combinations for a phase $p$ in a $P$ plase s!stein. we use the

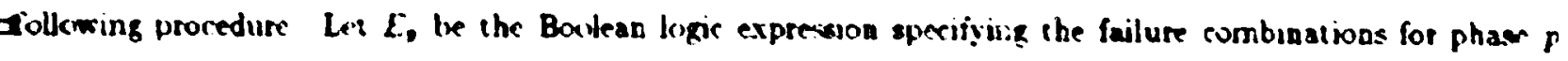
Then phace failure combinations which are treated as sucease conibiranors for all the subsequent phases and repair to success combinalioas for phase f. combicely decoled ac $(P F(p)$. are given by:

$$
F F C_{r}=\left(\cdots\left(\left(E_{p} \wedge \overline{E_{2+1}}\right) \wedge \overline{E_{1+3}} \cdots \cdots, \overline{E_{p}}\right)\right.
$$

In the ahove expression. wr inciude only thowe coritinations which are failure rombinations in phase $p$ but are anct failure combiaations in any of the subeequent phases. This expression can be simplificd as

$$
P \Gamma C_{r}=E_{q} \wedge \overline{\left(E_{p-1} \vee \cdots \vee E_{p}\right)}
$$

The form of the expression are the sume: as tha: is guven in. 112? Meadet who is familiar with the work in 
[12! should be careful while reading the strtion as there are a few difference for the algebra here from the one drseribed in [12]. The rules for manipulating expression are different to account for repairs. In fact. they are same as applicable for Boolean algebra and the special treatment for non-repairable systems as in [12! 5 not required ans more Also. the computation of piobability requires further attention.

\subsection{Thase Algebra}

Let $F=1$ inesu that companent $X$ has failed. Then $x=0$ implies that comporent $X$ has failed and $x=1$ means that composent $X$ is operational. lising this gotarion. for the system described in Figure 1 . there is only one possible configuration but the component used in a plase changes from phase 10 phase. Thus. the following Boolcan expression describe the failure for any phase. Also the compenent not being used in a phace is assumed to be repairnt.

$$
S E X I=F
$$

Similarly for the system deeeribed in Figure 2 the following Boolean expressinns describe the failure combinations for phases using $O R$ or $A Y D$ configurations

$$
\begin{aligned}
& \text { ORE }(X, Y)=I+y \\
& \text { A.XDEX.X. } y)= \pm 5
\end{aligned}
$$

Yotice tbat $X$ and $Y$ are only parameters here and whll be replaced by $A B$. or $C$ depending on the use of componeats It should also be nored that even: 1 denotes the failure of companant $X$ in that phase only: Thus for each phase. we aerd to define a exparale symbol for each composect This is very similar to Eeary and Ziebras botation where they have a eeparale symtol denoting faluse of a component in each phase Let $x_{1}=1$ denote the event that compmnent $X$ is cperational duritg $p t e x$ This is ierepectice of the status of that component in any previous phase. With this addition. the Boolean expression for phase $p$ for system $l$ is given by the following.

$$
E s,(x)=F
$$

Similarly: the crpressions for system 2 berome

$$
O R F_{y}\left(X, Y:=\bar{F}+\overline{y_{p}}\right.
$$

and

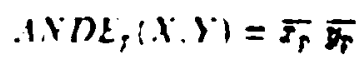

recpecrively. 
Csing the above two phases. it is possible that a system may be have iN $D$ sonfiguration in phase p followed by $A N D$ or $O R$ configuration in phase $p-1$ or $O R$ configuration in phase p followed by $A . N D$ or $O R$ configuration iu phase $p+1$. The four passible combivasions PFCs for phase $p$ assuming that phase $p-1$ is the last phuse. components $X$ and $Y$ are used in phase $p$, and components $Y^{\circ}$ and $Z$ are used in phase $p+l$ are given in Equation s.

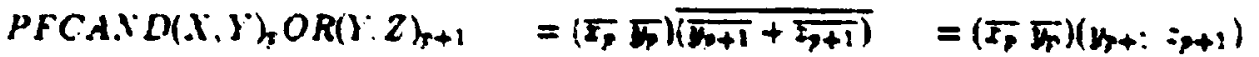

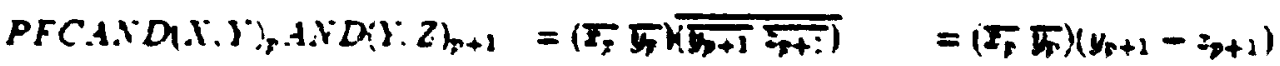

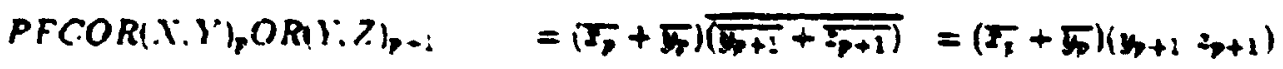

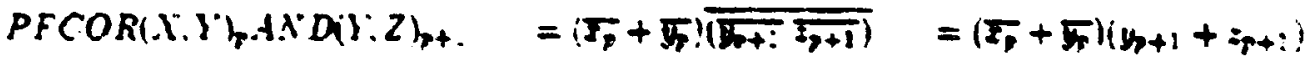

When the expression for PFC; is simplified. regular Boclean algebra rules can be applied. For this purpose. if $p$ and $q$ are two phoses. then $x_{g}$ and $x_{q}$ must the rreated as separate iariables. Tbe normal Boolean algebra rules such as $x_{p} z_{p}-x_{p} \bar{F}_{p} \bar{x}_{p}-\bar{T}_{p} \bar{I}_{p} x_{p}-0$, and their dual apply. Any product terms involving $x_{p}$ of $x_{p}$ or their complenents nust be reiained as it

An exprtssion such as $x_{p} \bar{F}_{p}$ means that component $X_{\text {is }}$ is operational at the end of phese $p$ but fails hy the tirue phase $y$ is fanisbed. On the other hand. an expression like $\bar{x}_{r} x_{1}$ unplies that companent $X$ is failed at the end of phase $p$ but is operational at the end of phase $q$ due 10 repair carried out during the process. Thux. if

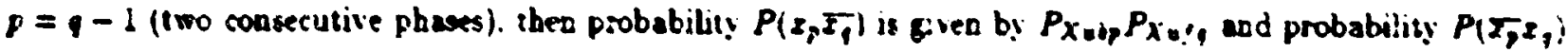
is given by $P_{x}$ ir $P_{x j u f}$. Otbe: sombinations are evaluated in a smilar fashion. If me repair is carried out then $P_{x ; u}=0.0$

\subsection{System Unreliability}

Uwing the phase success criterias for different phemen and phase algetira we compute the syskem unrehatility as followis For a $P$ phax systrm. we first compute the PFC, is for all phaves assuming $P$ as the last phase. Then the sy stem unpeliahility is given by

$$
i R=P\left(E_{F}\right)+\sum_{i=1}^{P-:} \operatorname{Pi} P \Gamma(;)
$$

where $P\left(E_{P}\right)$ is the probability of failure evaluated waig the fauls tree $E_{P}$ of phase $P$ (the last phax) and the failure distribution functicon calculaced for each componeat as described in Sertion 3. P(PF, , is the probability of phase failure combinations for phese $p$

Interpretention of Booloan Expressions While computing probatilities of PFC, s. derived abrive, we may

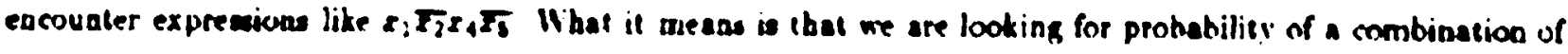
events where Component $X$ remant operational up to the end of phase 1 . fails by the tume phase 2 ends. hut is 
opetational again by the end of phase 4 . and then fails by the time phase $j$ finishes. The following tree is useful in explaining bow to compute the probability of this combination of events for component $X$.

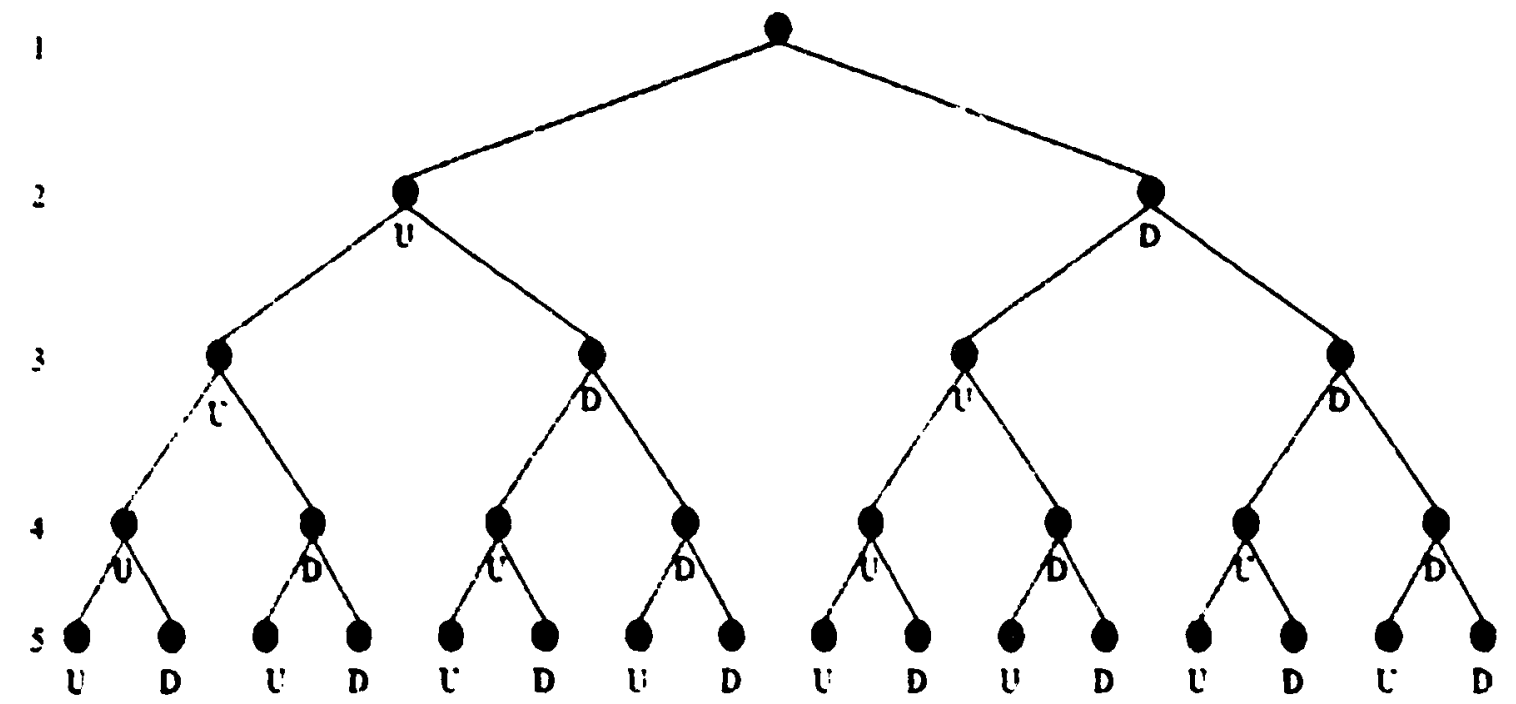

Figure 4 A romponent up; fai! tree ore: multiple phases

In the tree if we assune that the root at level $l$ is nepresenting an event that composent $A$ is up al the end of phase 1 (there is certain probability anceciated with it), then the left child (at level 2) is representing that It is up at the end of phase 2 and the right child (at berel 2) is reprearneing that it is failed. We can compute the probabilities of these events using exprescions for $P_{X u+z}$ and $P_{X u / 2}$ from phase 2 paramevers. Similar interpretalion exists for children of level 2 indes from phase 210 phase $3 \approx$ the component statr changes. To go from Componeat $X$ has failed at the ead of phase 2 to the state that it is operational at the end of phase $t$.

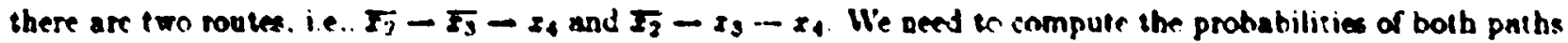
and thrn add them up io arrive at the probatility of rombination 5 zist $_{4}$

He may encounter any enmbination of such events for a component but it should be obrious that such computations are required to he done for each component and oor for systern siates. For a componens. if there ase $p$ phases. then there of mont $x+$ : values which we need to store. In an $X$ component system, this amounts

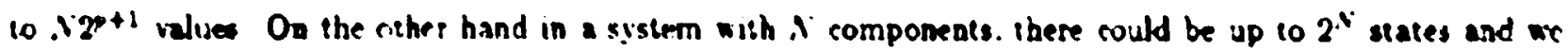
bave 10 analyze tbern for p phame So we may be sloring up $10 \mathrm{p}^{\circ}$ stutes combination Normally. $I>>$ f i will not be the case for examplos in the papes for the obviou reasons!. Thus tbe technique bere is computalios all! much more efficient then grompating a stace space and computung state occupation probabilities for tho ates for cach phar given a distribution from a previous phase oprsating. 


\subsection{Computing Transient Behavior}

In the previous sertiou. we outlined the mechanism to compute unseliability at the end of a miscion, that is. the end of the last phase. Sometime one may be interested in computing the unreliability hehavior during all phases. This means we need to compute unreliability for each phase as a function of time. It turns cut that this is not expensive and can be easily accomnodated in ous methodology as the PfCs calculation is recursive.

Recall that PFC's for a phase are computed as

$$
P F C_{r}=E_{r} \wedge \overline{\left(E_{p+1} \vee \cdots\left(E_{P}\right)\right.}
$$

Also. the unreliability at the end of a mission is computed uning the expression

$$
l R=P\left(E_{P}\right)+\sum_{i=1}^{r-1} P\left(P F\left(C_{p}\right)\right.
$$

Lu a Phase system, we defiue $P F C_{P}=E_{p}$ theli che unreliability for $P P$ phase sustem can be wrizten as

$$
\because R=\sum_{r=1}^{P} P(P F(;)
$$

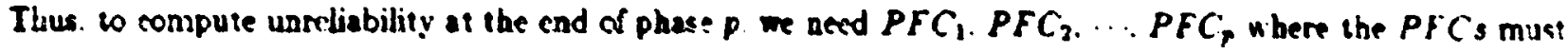
be calculated using phase $f$ as the last pbase. He define $P F C_{1}$; as the $P F C$ of phase $i$. $i p$. ncsuming prase $p$ as the last phase. Then the following relation holds.

$$
P F C_{1,}=P F C_{1,-1}, E_{1}
$$

The unreliability of the ph phase is computed by using the following melation

$$
\left(R_{r}=\sum_{i=1}^{r} P_{i} P F C_{1},\right)
$$

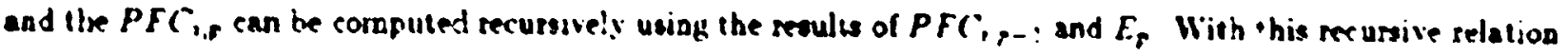
one may compute reliability of phase $r$ using the result of phas $p-$ :

\subsection{Latent Failures}

It should aleo be soliced that at the tranaition of a phase. One may see a upwards change in uarebability value at the phase irnosution tume. This happens if the next phase has different succras critesis than the curreat phase. In that case it is positile that that some of the success stutes in phase i may the failed atates in phax $i-1$ We

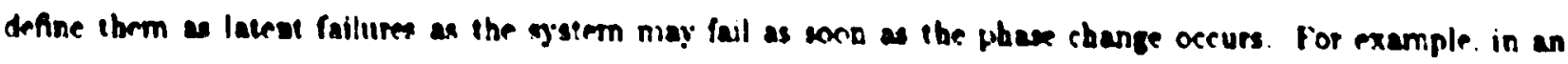

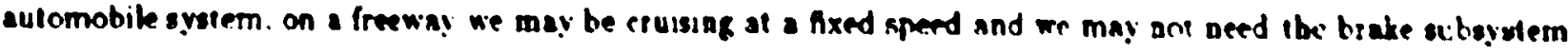


w a car. But as scon $\%$ we bit a city linsit, a phase change occurs and if the brakes are not fully functional we are likely to bis some orher vehicte. To compute unseliability increase due to phase change from phase ito phase $i+1$, we compute $l \cdot R_{i}$. Then, we compute $l ' R_{i}$ - which is just after the ead of phase $i$ and beginning of phase it 1. For this purpose. we modify the surces criteria and $i t$ is now a bejial sum of the sureces criteries of pheses $i$ and $i+1$ evaluated at the end of phase $i$ using parameless of phace 2 . We define this as $L_{1}=E_{1}+E_{3+1}$ with $E_{1+1}$ specified using component status at the end of phase $i$. PFCs also amed to be recvaluated as $L$, inslead of $E$, for the phase $i$ (for carliet phases. we will still we $E_{F}$ and not $I$, for $p<i$ ).

We rill demonst rate our methoudogy using the examples descrited above in the following errion.

\subsection{Example Computations}

In the first example. we use the txo ccraponeut system with fout phases. In the first phace, we require component A for operation (and therefore there is uo repait on it. discussion above in Section 4: Component $B$ has associated with it both failure and repair rates. Tben we alkernate between the use of compouent and repair Thus the succrss eriterias for four phaser are specified hy

$$
E_{1}=S E_{1 i} 1:=\sigma_{2}: E_{2}=S E_{2}\left(B !=\sigma_{2}: E_{3}=S E_{3}(1)=\sigma_{3}: \quad E_{4}=S E_{4} ; B\right)=\sigma_{1}
$$

lising the above infurmation, at the phase changes from $p$ to $p+1$, there could be laseri failure ithey are in this system ind to evaluase unreliability including phaxe change boundary. we will use $L$. instead of $E_{\text {; }}$ s discused shove. The sticerse criteria with latent failures is given by

$$
L_{1}=S E_{1}(A)-S E_{:}(B)=\sigma_{!}-\delta_{:} \quad L_{2}=S E_{2}(B)+S E_{2}(A)=\delta_{2}+\sigma_{2} . \quad L_{3}=S E_{3}(A)+S E_{3}\left(B !=\sigma_{3}-\delta_{3}\right.
$$

He acoume that there is no phase change after phaxe + tising this information we can compute PICs as follows.

$$
\begin{aligned}
& P F C_{12}=\left(E: E_{9}\right)=\bar{\sigma} b_{2} \\
& P F C_{1 s}=\left(P F C_{1:} \cdot E_{3}\right)=a_{0} b_{20} \\
& P F C_{23}=\left(E_{2} \cdot \bar{E}_{3}\right) \quad=\sigma_{90} \\
& P F C_{14}=\left|P F C_{13}, \overline{E_{1}}\right|=\sigma_{1} b_{2} a_{1} b_{4} \\
& P F C_{21}=\left(P F C_{23} \cdot E_{i}\right)=\Gamma_{203} b_{4} \\
& P F C_{34}=\left|E_{3} \overline{E_{1}}\right|=\overline{\sigma_{3}} b_{4}
\end{aligned}
$$

Non to compute latent PFCs (that is including latent failures at the phase transition points). we use sbe aume exprermions except that we noed is $L$, instead of $F_{i}$ and ohtained the follow ing LPFC. Nolice that in the rerursice function. we continue to us. PFC and $L$, is only used for the current last phase 
Table 1: State Probabilities and Lureliabilities for a ino component system

\begin{tabular}{|c|c|c|c|c|c|c|c|c|}
\hline State & BP1 & EP1 & BP2 & EP2 & BP3 & EP3 & BP4 & $k$ \\
\hline Prator & 1.000 & 1.000 & 1.000 & 0.891 & 0.891 & $0.891^{2}$ & $0.891^{2}$ & 0.84 \\
\hline 11 & 1.000 & 0.891 & 0.891 & 0.891 & 0.891 & 0.891 & 0.891 & 0891 \\
\hline 10 & 0.000 & 0.009 & 0.000 & 0.099 & 0.000 & 0.009 & 0.000 & 0.099 \\
\hline 10 & 0.000 & 0.099 & 0.000 & 0.009 & 0.000 & 0.099 & 0.000 & 0.009 \\
\hline 00 & 0.000 & 0.001 & 0.000 & 0.001 & 0.000 & 0.001 & 0.000 & 0.001 \\
\hline IR & 0.000 & 0.100 & 0.109 & .1981 & .206119 & 0.2855071 & 0.29265203 & 0.36338683 \\
\hline
\end{tabular}

$$
\begin{aligned}
& \angle P F C:=\left(E_{1} \cdot \overline{I_{2}}\right) \quad=\sigma_{1} a_{2} b_{2} \\
& \angle P F C_{13}=\left(P F C_{12} \cdot T_{3}\right)=\sigma_{1} \text { hagnos }_{3} \\
& \angle P F C_{23}=\left(E_{3} T_{3}\right)=\bar{b}_{2} a_{3} b_{3}
\end{aligned}
$$

Thea the unreliability at the end of phase $p$ and at the beginning of phese $p+1$ is given by the following expressions.

$$
\begin{aligned}
\left(R_{p}\right. & =\sum_{i=1}^{r-1} P\left(P F C_{i, j}\right)+P\left(E_{,}\right) \\
U I^{r} R_{r} & =\sum_{i=1}^{r-1} P\left(L P F C_{(j)}\right)+P\left(L_{p}\right)
\end{aligned}
$$

We computed aumerical results usirg above expression and paramelers values which are easy to verify hy hand computation. Wr first ueed phase durations for each phan an 10 bours and value of frulure and repair rates for both components in such a way that the factor a at phase duration of 10 hours is equal in 0.9 . Also, if repaut is applicable, then parameter to in all phases for applicable mmposents is alse 0.9 "sing. thexe parameter ialues. we get the resulis shown in Table 1. Here BP and F.P st ands for begianing of phoce and end of phace and we are cabulating SOP for each state. reliability, and ubreliability and we have a multiplicawion factor amociated with all column entries Idea is to be able so ciraply see that the reculta are corret Tbe resulu are obtaibed using SHARPC [2] program where PFC expressions wem hand conded. EAARP [10]. aod hand calculackans the results match in all eases to 9 agnificane digits. The multipliention faccor only applies to SOPa and the ubreliabilin! values arr an they are lased

To give a betlet idea appreciation for results and march the resulss of this table to that obtained wing Maskon chain andrais. Ile. Markov chaipo and the saitsal atate oxcupation probabilitien for four phanes are sbown in Figure 5 Any stace occupation probability nor abown wero (that is the case for three anates our of four ill every pbuae! I wo of the stales are failure states is each phem. One of the remainiag swo motes heromes - latent falure stute I bus ouly one stote is operational siate at the beginaing of each phase. 


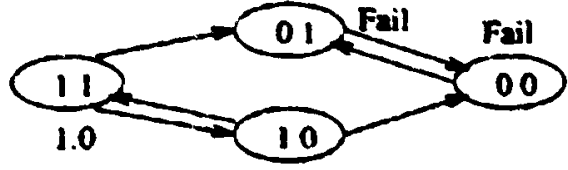

Phasel

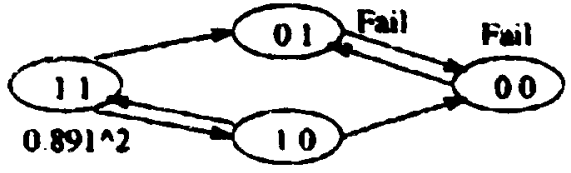

Phase?

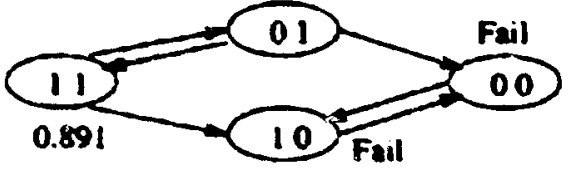

Phase?

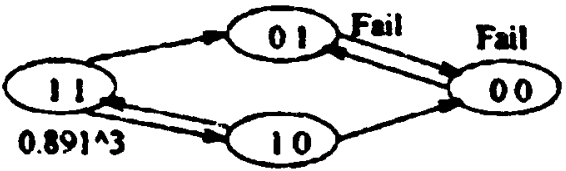

Phased

Figure 3: Narkov Chains for four phases with initial SOPs

Table 2: Inneliabilities fox a two componepr susterm: (variable parameters)

\begin{tabular}{|c|c|c|c|c|c|c|c|}
\hline Cece & E.P1 & BP2 & EP2 & BP3 & EP3 & BP4 & EP4 \\
\hline $1\left(\times 10^{-4}\right)$ & 0.99995000 & 1.631880093 & 2.631767i4 & 3.263695553 & $4.2633191 i$ & 4.89 .314383 & 3.89460434 \\
\hline $2\left(\times 10^{-4}\right)$ & 0.999950000 & 199990001 & 2.099935004 & 3.99921011 & $4.99873 \mathrm{C21}$ & 5.99820036 & $6.9975505 ?$ \\
\hline $3\left(\times 10^{-3}\right)$ & 0.99950016 & $1.09938 \mathrm{ji} 0$ & 2.09778703 & 2.19736275 & 3.19486643 & 3.29453247 & $4.290739 i 3$ \\
\hline $4\left(\times 10^{-3}\right)$ & $0.999 \times 30016$ & 1.99800133 & 2.99550451 & 3.99201066 & 1.98732081 & 3.98203595 & 6.97535707 \\
\hline $5\left(\times 10^{-4}\right)$ & 0.99993000 & 1.06315347 & 2.06299916 & 2.12619791 & 3.12593531 & 3.18912734 & 4.18875844 \\
\hline $6\left(\times 10^{-4}\right)$ & 0.99995000 & 1.09993950 & 2.09977932 & 2.1997 .5802 & $3.1994 \times 80 j$ & 3.29843556 & 1.29007563 \\
\hline$i\left(\times 10^{-3}\right)$ & $0.99950 \quad 16$ & 100918962 & 2.00798080 & 2.01796017 & 3.01544335 & 3.02341268 & 4.02188694 \\
\hline $8\left(\times 10^{-3}\right)$ & 0.99930016 & 1.09939322 & 2.09799634 & $2.1975 \times 175$ & 3.14483546 & 3.294561298 & 4.29076824 \\
\hline
\end{tabular}

Vext we used other data $t 0$ compute the results. In all cases the repair rale if applicable remains wo be 0.100 / hour. Io tbe fint four caner. we use failure rate of each componedt irrespective of usage $n 0.00001 /$ hour. In the lant frour cases. we un failure rates of used components a 00000 1/bour while thouc under repair as

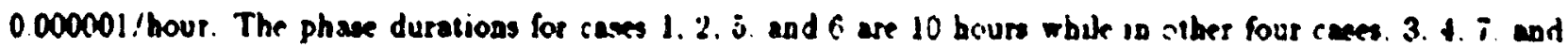
8 , are 100 hours. In even aumber canes. the analysis is dooc by ignoricg repars while odd cass include repairs Table 2 contain the results obtained in all caxes.

First motice the multiplication factors for exch row. A fector of 10 difference a thete due to the massion (phere) times. Yext. when we ignore repain we trolice a sutatantial change in uscliability values obtained in the Arat four cases when the failure sales are the same whetber a component is being repared of not Thus repairs milst be acerwinted for in such cases. More interesung results are obtannd wbed the componeats being. repaired heve an order of maguitude smallet falure rates (capes 5-8) In these eans ignoring repairs impack the 
resulks but in this example the difference is not substantial. So one may chocke one is another analyais based on parameter values.

Example 2. For example 2, we consider the three components, A. B. and $C$. systetu with two phase configurations AID and OR and thre pheses. In eacb phase one component is nor used. Suppose component $A$ is nos used in phase 1, component $B$ is not used in phase 2. and component $C$ is not uned in phase 3 . There are

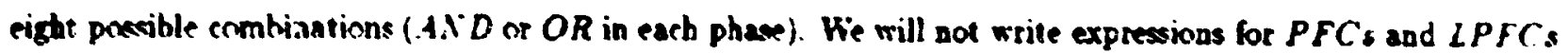
for all caces here. But to demonstrate how to derive them. for one case when Phase 1 is OR(B. (). phase 2 is $A . P(C . A$ ) and phase 3 is $A . N D, A, B)$. Then

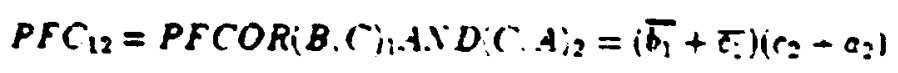

and

$$
P F C_{23}=P F C A N D C C_{1}+1_{2}+A N D(A, B)_{3}=\left(\bar{c}_{3} \sigma_{2}\right)\left(a_{1}+b_{3}\right)
$$

as computed in lquation s. Wie can also enmpute $P F C_{19}$ using the recurrence relation to obiain

$$
P F C_{: 3}=P F C_{12} \overline{E_{3}}=\left(\overline{b_{1}}+\overline{c_{1}}\right)\left(c_{2}+a_{2}\right)\left(a_{3}+b_{3}\right)
$$

To compute the probabilities of these expressions. we need to expand the expression in mutually cxclussice terms. It should be noted that when expressions are in product of expressions form, each product expression can be indepeadently expanded into mutually exclusive terms. Thea a product expansion will give all terms wbicb ar mutualis exclusive. So using this. we compute probabilities of PFCs as given below for this cace.

$$
\begin{aligned}
& P\left(P F C_{: 2}\right)=P\left(\left(\overline{\sigma_{i}}+\bar{\tau}_{1}\right) i_{2}+c_{2}\right)=P\left(\left(\bar{\sigma}_{1}+b_{1} \tau_{1}\right)\left(a_{2}-\bar{\sigma}_{2} c_{2}\right)\right) \\
& =P\left(a_{3} \bar{\sigma}_{1}\right)+P\left(\sigma_{2} \bar{\sigma}_{1} c_{3}\right)+P\left(a_{2} b_{3} \bar{c}_{3}+P\left(0_{2} b_{1} \bar{c}_{2} c_{3}\right)\right. \\
& P\left(P F C_{1}\right)=P\left(\left(\sigma_{1}+\tau_{i}\right)\left(c_{2}-a_{3}\right)\left(a_{3}-b_{3}\right):=\left(\sigma_{1}+b_{:} \tau_{!}\right)\left(a_{2}+\sigma_{2} c_{2}\right)\left(a_{3}+\sigma_{3} b_{3}\right)\right. \\
& =P\left(a_{3} a_{3} \delta_{1}\right)+P\left(a_{3} a_{3} b_{1} \pi_{1}\right)+P\left(a_{3} \sigma_{3} \sigma_{1} b_{3}\right)+P\left(0, \sqrt{3} b_{1} b_{3} r_{1}\right)
\end{aligned}
$$

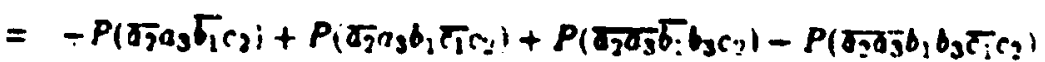

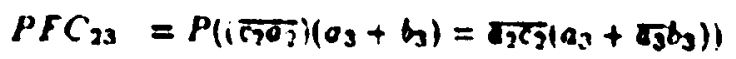

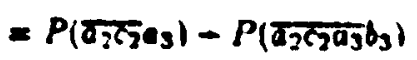

We progriammed each of the eight pomitle rame. We uned failuse rate for each component wo be $0.0001 /$ hour and repair race co be $0.1 /$ hour whereever applicahte in 10 hours/pbase miseiog. The reauls for cight caces are

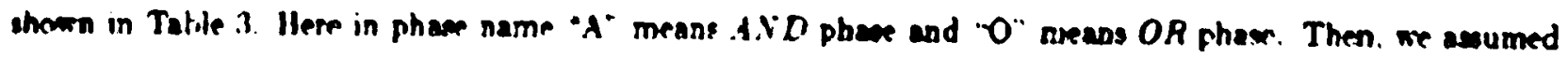
that the failure rate fot the component under repair is all i c. 000001/hour and recomputed all the eight canes. These results are in Table 4. One can notice the difirrence in uareliability in the live cases. Wie are nos sbowing the results when we ignore the repains aliogether but, we noticed that the difference $n$ sigaificant in the first cae and relatively lese in the second case. 
Table 3: linreliability for eight cases with same failure rales

\begin{tabular}{|c|c|c|c|c|c|}
\hline Case & EP1 & BP2 & EP2 & BP3 & EP3 \\
\hline AAA & $9.99000583-0 i$ & $1.629909932-06$ & $4.25356226+06$ & ¿ 88170181-06 & $9.49979360<-06$ \\
\hline OAA & $1.99800133<-03$ & $1.99800133 r-03$ & 1.99962790e 03 & $2.00065528 e-03$ & $2.00390329-03$ \\
\hline AOI & $9.99000583 \mathrm{~A} 0 \mathrm{~T}$ & $1.63072502 \mathrm{e}-0.3$ & $3.625+681$ ie-03 & 3.6254681 ie-03 & $3.62 i 45761 e-03$ \\
\hline $\mathrm{OOA}$ & $1.49800133-03$ & $2.62839 .32 k e-03$ & $1.62134468 \mathrm{e}-03$ & $+62134468-03$ & $4.62296705-03$ \\
\hline A.1O & $9.990005 x 3=07$ & $1.62990993 e-106$ & $4.25 .536226 e-06$ & $2.62891027 e-03$ & 1.62165904-0. \\
\hline 0.10 & 1.998010132 e 03 & $1.98800133<-03$ & $1.99962799 \mathrm{e}-03$ & +.6223933 te -03 & $6.24453336+03$ \\
\hline .100 & $9.99000583<-0 i$ & $1.63072302 \mathrm{e}-03$ & $3.620+681$ ie-03 & $162103010-03$ & 6.6097986le-03 \\
\hline 000 & $1.99810133=03$ & $2.62839528 \mathrm{e}-113$ & $4.6213+168<-03$ & j $25029105-03$ & $\div .23 \pi 7923:-03$ \\
\hline
\end{tabular}

Table f loreliability for eight cases with inx failure rates for conponents while under repair

\begin{tabular}{|c|c|c|c|c|c|}
\hline Case & EP1 & BP:2 & EP? & BP3 & EP3 \\
\hline IAA & $9.090005 \times 3+07$ & $1.06211325 e \cdot 06$ & $3.12110783+06$ & 3.37825367 ie-16 & 6.064926 ite 06 \\
\hline 0.1 .1 & $1.99800133+-03$ & $1.98800133 \mathrm{e}-03$ & $1.90906133<-0.3$ & $1.99912820-03$ & $2.00124603 \times-03$ \\
\hline AOA & $9.980003 \times 33-0 i$ & $1.06264640-03$ & $3.0535245 i-03$ & 3.0563245 ie-103 & $3.05994942 e-03$ \\
\hline OOA & $1.90800133-03$ & $2.06108445+-03$ & 4.031967 ite -0.3 & 1.054967ite-03 & $4.03602355-03$ \\
\hline A.1O & $9.990003833-07$ & 1.06211326e-06 & $3.12110793-06$ & 1.4936873te-03 & $3.488704486-03$ \\
\hline 010 & $1.00800133-03$ & $1.99800133+-0.3$ & $1.990006133-03$ & 3.4888:187e-03 & $5.11330314+03$ \\
\hline$A(x)$ & $9.980 \times 03 \times 3-07$ & $1.0026+6+0 e-0.3$ & 3.05852+5ie-03 & $3.4 \$ 80-495 x-03$ & $3.47910711+03$ \\
\hline 000 & 1.99senno1.31e-03 & $2.0610844 j e-03$ & 4.054967ite-0.3 & 4.11792034-03 & $6.107691566-03$ \\
\hline
\end{tabular}

Table 5 "nreliatility for "all is well if end is well" case

\begin{tabular}{|c|c|c|c|c|c|}
\hline Case & EP! & BP2 & EP2 & BP3 & EP3 \\
\hline ash $R$ & $1 . \times 913 i 172+03$ & $1.89+37172 \mathrm{e}-03$ & $2.525-12938-03$ & $232542934+-03$ & $3.38726223 \times$ C3 \\
\hline $0, x$ & $2.1055,0450-03$ & $2.98530450 \mathrm{Cr}-0.3$ & 3.9930056 ie 03 & 3.9430056 ie-03 & $5.97905190-03$ \\
\hline$\because 3 n R$ & $2.322639 .23-10$ & 6.32235388n-C4 & 8.6481ilsie-04 & $2.3 \times 997399+03$ & $3.390+16756-03$ \\
\hline , 3kin & $998301249-10$ & $1.00049817-03$ & $2.0019853 i-03$ & 3.932012595-03 & $8.93962123-03$ \\
\hline
\end{tabular}


Example 3. In cur last example. we programmed the third case where the thee phases are $a=O R, \beta=$ $O R-A N^{\prime} D$. and $?=O K$ as shown in Figure 3 . We ran four cases for this example. These had two ordess a $3 y$ and $Y^{\text {iha }}$ and in each case there is repair on all romponents in all phoses (R) ce no repair on any component (N). The phases are each of 10 hours durations. The falure rates for each component in each phase is 0.0001, hous. The repair rntes for each component when appicable is $0.1 /$ hour. The results are shown in Table $\mathfrak{j}$. Yotice iwo things. Once ignoring repairs bave significant impact on uareliability due to repairs, in particular for the system where the success criteria is more stringent during the later phsses. With repairs the unreliability can be almost maintained at the same levels as is the case in the first and the third line.

\section{Managing Phased-Mission Systems with Repairs Using RBDs}

It sbould be mentioned that this analysis cas also be cartied out using RBDs. Recall that in [5] each component $x$ model in pbase $p$ is replaced by a series of everits $x_{i} x_{2} \ldots x_{r}$. In case of repairs. sach component model will be a parallel series model derived out of companent up/fail tree ss shown in figure 4 . There will the up to $2^{-:}$paralle! branches. Each branch represents one unique pach from root to one of the leaf $l$ node in the tree. Notice that if a particular phase does not have repaur on a particulas corr.pcinent, then the tree does not have anc exparsion from that the iatermediate $D$ node in the iner The rest of the analysis remains the same.

\section{Conclusions}

We have presented a techajque 10 analyze phaned-mission systems including component repairs whowe phase success criterias can be exprexsed using fault irees. This technique yiclds accurate resulu and is sirnple in concep: and computation. For this purpose, we eahanced phase agebra to include the effects of phases that alkers us to efficiently compute the probubilities of all possible combinations contributing to failure in phasedmiscion systems during indisidual phases. This tectnique ss very useful for a large class of systems where during the long nussion tinew the system includes repairs but syetem operational behavior can be described using fault irea. Several examples bave been ancluded to show the efferts of repairs and how to auanage it computationally Currently we are incorporatiag these techn:ques in reliability analysis tools 


\section{References}

[1: K. Trivedi. J. Dugan. R. Geist. M. Smotherman. B. Rotbmann. M Bayd. and S. Bavuso. HARP: Introduction and guide for the users." Dept. of Computer Science. Duke Inivessity. Durbam. VC 27j06. March 1486 .

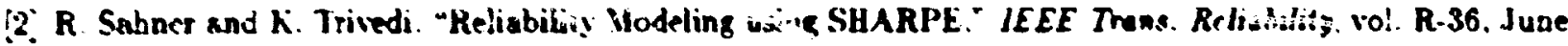
1987. pr. $186-193$

[3] A. Goyal. W. C. Carter E de Domes e Silia and S. S. Laventerg. "The System A vailability Estimator," is Pror. of ETCS-16. June 1956. pr. 8t.39.

if] R. Butler. "The SI'RE: Reliabilus Analysis Program." AlA.A Gudonce. Nizugotion, and Control Conference. Hilliamsburg. Virginis. August 1986.

[5] J. D. Ecary and H. Zisbms. -Reliability Analysis of Phased Mliscions." Prex of the Conf on Reliabihty and Fealt Tree trebses. SIA.Y 1975. pP. 213-236

[6] A. Pedar and V.Y.S. Sarma. "Phased-Miesion Analysis for Evaluating the Effectireness of Aerospace Computing-Systems." IEEE Trons o- Rel., vol. R.30, No. 5, Der 19:1. pp 429437.

(i) M. Alarn aod C. Al-Sagzaf. "Quantitative Reliabiiity Evaluation of Repairable Phased-Mliasion Systems

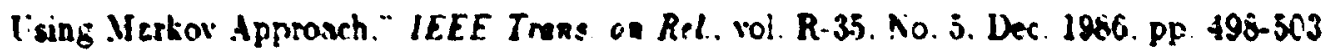

(N) J.B. Dugan. "Automated Adalysis of Pbasent-Afiscion Reliability:" IEEE Inens. ("n Rel vel R-40. No 1. April 1991. pr. 45-51.

[9] M. Smotberman and $\boldsymbol{k}$. Zemoudeh. A Von-Homogeneous Markor Model for Phased-Mlission Reliatility Analysis." IEEE Trane nn Rel. vol. R.38. No. 5. Dec. 1939. pp. 585.54)

[10] A. K. Sxmani, J. A. Rutecy, and S. Au. Tomputationally Efficieat Phaseri-Mission Reliahility Anaiysis for Systems with Variable Configuration." IEEE. Trans. on Rel. wol R-42. Dec. 1992. pp. 304-303

[11] A. K. Somani. S. Paluitlar and T C. Sharma "Heliability Modeling of Systems with Latent failures using Markor Chains,- Proc of R.1.VS.95. pp 120-12i

[12] A $K$ Sumani and $K$. S. Trived. 'Phased-Mission System Analysis I'sing Boolean Algebrac Mletbods." in the Pror. of Sigmetrics. 19094. pp. 98.10i

[13). . Veeraragbasan and $k \mathrm{~S}$ Trivedi. An linproved Algoritbm for Symbolic Reliahility Analysus." IEEE: Trens. on Rel., vol R-10. No 3. Dre. 1991. pp. 311-356 
[14] K. S. Trivodi, "Probability \& Statiatica with Reliability, Queuins, and Computer Scieoce Applieations," Premticontill, INC, Endewood Ciff, NJ. 


\begin{tabular}{|c|c|c|}
\hline \multicolumn{2}{|c|}{ REPORT DOCUMENTATION PAGE } & 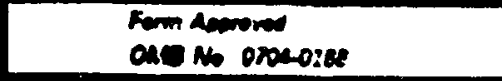 \\
\hline \multicolumn{3}{|c|}{ 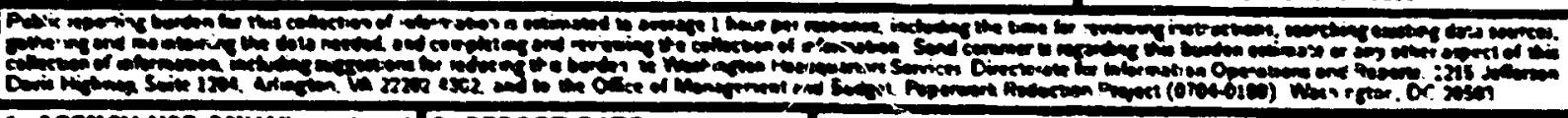 } \\
\hline 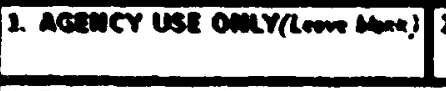 & 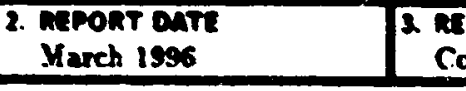 & $\begin{array}{l}\text { 3. REPOAT TrPe ADO DATES COVTRED } \\
\text { Coatructor Report }\end{array}$ \\
\hline \multicolumn{2}{|c|}{ 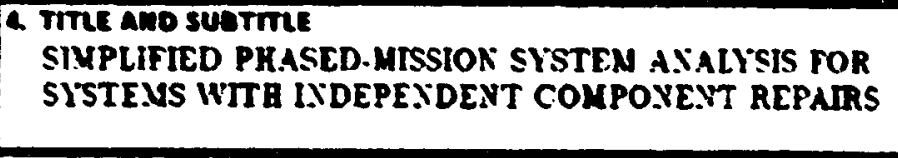 } & $\begin{array}{l}\text { C NAS1-19480 } \\
\text { WT SOS.92-52.01 }\end{array}$ \\
\hline \multicolumn{3}{|c|}{$\begin{array}{l}\text { AUTHon(s) } \\
\text { Arun K. Somani }\end{array}$} \\
\hline \multicolumn{2}{|c|}{ 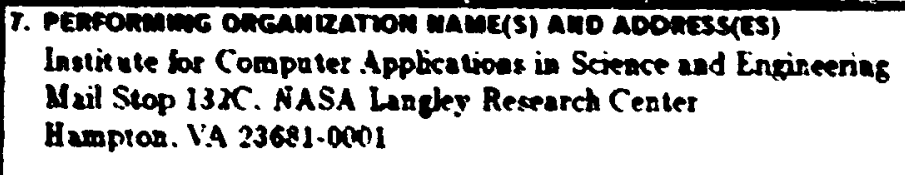 } & 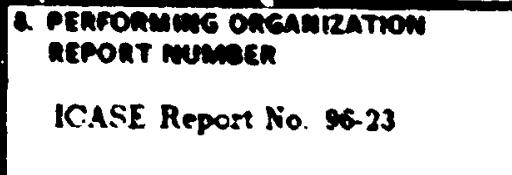 \\
\hline \multicolumn{2}{|c|}{ 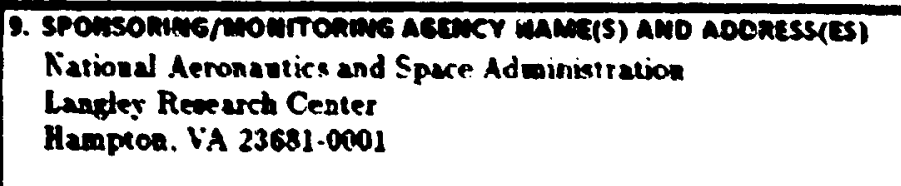 } & 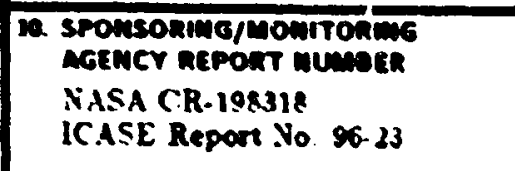 \\
\hline \multicolumn{3}{|c|}{$\begin{array}{l}\text { 11. SUpplementany notes } \\
\text { Langley Technical Mouitor: Deanix N. Eushnell } \\
\text { Fiad Report } \\
\text { Submiltred tn Sigmetrice 1906. }\end{array}$} \\
\hline \multicolumn{2}{|c|}{ 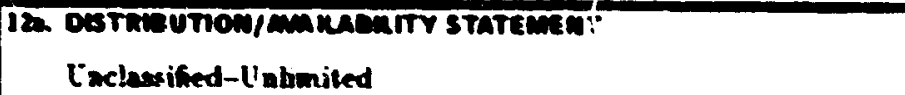 } & 12m. OSTARUTIOA COOS \\
\hline \multicolumn{3}{|c|}{ 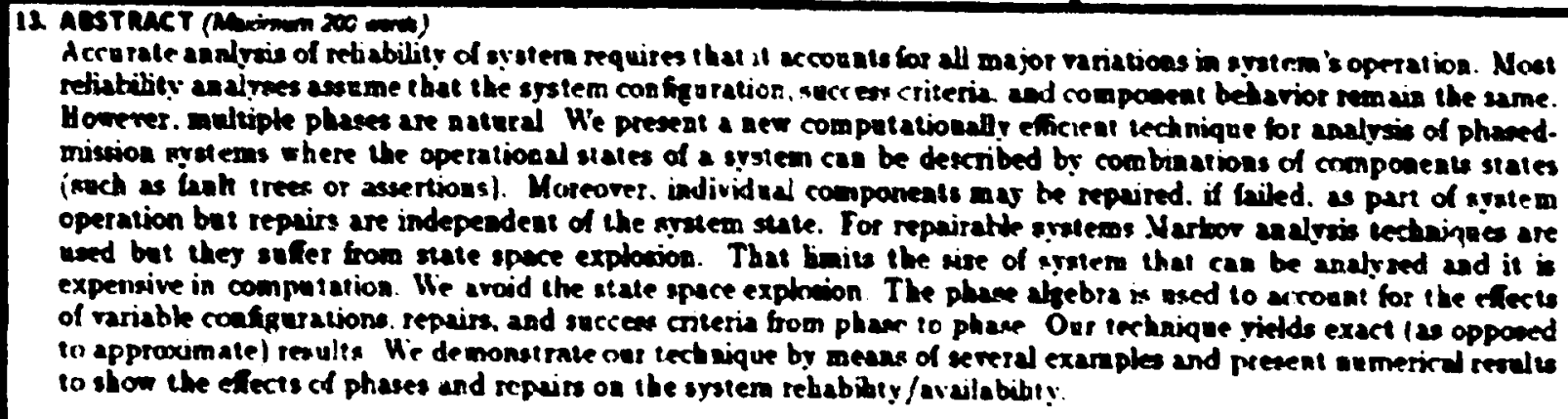 } \\
\hline
\end{tabular}

\section{4. suject rinus}

Phaned Mliavion Swotems Independeat Component Repuirs: Repair Phaces:

Vlera-Reliable Srmem. Rebabihiy Analysis: Booken Algebruc Nethods:

Faull Tres: Vejuble Succeve C'piteria: Reronheration

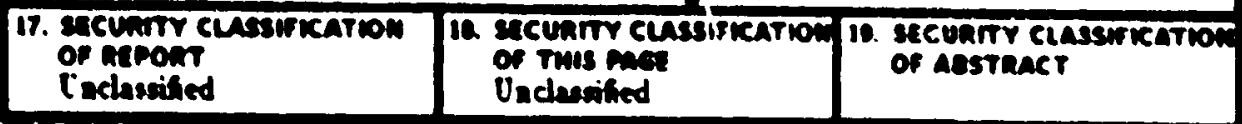

